\title{
Sentidos do trabalho e formas de participação: o caso de uma cooperativa de trabalhadores rurais do Assentamento Mário Lago, Ribeirão Preto (SP)
}

\author{
Thainara Granero de Melo'1, Rosemeire Aparecida Scopinho² \\ Universidade Federal de São Carlos (São Carlos, SP, Brasil)
}

O problema da participação em cooperativas de trabalhadores rurais assentados têm sido estudado sob diferentes perspectivas, porém não há consenso na literatura. De todo modo, a literatura mostra que há diferentes fatores que contribuem para a falta de participação real dos trabalhadores, especialmente porque o acesso às políticas públicas está condicionado à criação de cooperativas ou associações, o que torna compulsório o associativismo. $\mathrm{O}$ objetivo deste artigo é discutir as formas de participação de trabalhadores rurais em cooperativas por meio da análise dos sentidos atribuídos ao trabalho. Estudamos o caso de uma cooperativa do Assentamento Mário Lago, Ribeirão Preto (SP), por meio de estratégias de observações diretas e de entrevistas semiestruturadas. Constatamos que a participação instrumental predominava no grupo, reforçada por dependências materiais, institucionais e afetivas dos sujeitos. Os sentidos atribuídos pelos sujeitos ao trabalho cooperado reforçaram a constatação de que o modo como as políticas de desenvolvimento rural têm sido pensadas no país traduzem a desproporcionalidade entre a prática cotidiana da cooperação e o cooperativismo institucionalizado.

Palavras-chave: Participação, Sentidos, Cooperativa, Assentamento rural, Psicossociologia.

Work senses and ways of participation: the case of a rural workers' cooperative of Mario Lago Settlement, Ribeirão Preto (SP), Brazil

The problem of participation in rural workers' cooperatives has been studied by different points of view, but the results are not consensual. In any case, the literature shows different elements that contribute to the lack of real participation of workers, especially because the access to family agriculture's public policies is conditional upon cooperatives or associations. The goal of this paper was to investigate the participation forms of rural workers into cooperatives through the analysis of the meanings attributed to work. We studied the case of a cooperative in Mario Lago Settlement, Ribeirão Preto (SP), Brazil, through observations and semi-structured interviews. We found out that the instrumental participation predominated in the group, reinforced by material, institutional and affective dependencies. The meanings given by the subjects reinforced the opinion that the way of rural development policies have been thought in country reflects the disproportionality between the daily experiences and the institutionalized cooperativism.

Keywords: Participation, Senses, Cooperative, Rural settlement, Psicossociology.

\section{Introdução}

participação é tema recorrente quando se fala em processo organizativo para o trabalho
associado e nos últimos anos tornou-se a palavra de ordem dos grupos, segundo Guareschi
(2008). Dentre os seus diferentes sentidos possíveis, seja em organizações autogeridas ou
heterogeridas, o que significa falar de participação em cooperativas de assentamentos rurais de
reforma agrária? Desde a década de 1980, quando o cooperativismo foi institucionalizado nas
políticas de assentamentos rurais de reforma agrária recente, a academia tem investigado como ele
se desenvolve nesses espaços: trata-se de um tipo de cooperativismo autêntico, comprometido com
os princípios da democracia participativa? Ou que apenas reproduz o modelo de cooperativismo
tradicional e típico do rural brasileiro, cujas origens estão relacionadas aos interesses dos
grandes produtores capitalizados? A literatura que trata desse problema não é consensual. Há
posicionamentos mais otimistas quanto ao potencial de participação dos trabalhadores rurais

1 Doutoranda em Psicologia no Programa de Pós-Graduação em Psicologia da Universidade Federal de São Carlos.

2 Professora associada do Departamento de Psicologia da Universidade Federal de São Carlos. 
assentados e outros que concebem as cooperativas como retrato dos mecanismos institucionais de controle político dessa população, sem que para isso ocorram mudanças na estrutura fundiária do país. Nesse caso, o estudo da participação é ainda mais complexo, pois o assentamento é uma unidade espacial de especificidades que comporta disputas entre as diferentes concepções sobre agricultura, reforma agrária e cooperativismo existentes na história brasileira. E é nesse campo de contradições que os sujeitos buscam ressignificar as suas experiências de trabalho e de vida.

Por mais que nos últimos anos tenham proliferado os estudos sobre cooperação e cooperativas no mundo rural, ainda não são claros os mecanismos psicossociais que atuam para configurar o problema da participação dos trabalhadores. A psicologia brasileira ainda não se apropriou com profundidade do rural como objeto de estudo, motivo pelo qual apostamos que a articulação entre conceitos da psicologia social do trabalho e da psicossociologia, por exemplo, pode contribuir para esclarecer os arranjos singulares de participação e os sentidos atribuídos às diferentes formas de trabalho. Trata-se da análise do cotidiano dos processos sociais em curso nas organizações de trabalho associado, em todos os seus níveis de realidade, desde o institucional, passando pelo organizativo e pelos aspectos de ordem afetiva e relacional (Barus-Michel, 2004). A investigação dos sentidos atribuídos pelos trabalhadores rurais assentados ao trabalho cooperado pode explicar o modo como eles participam do processo decisório das cooperativas, bem como contribuir para esclarecer os mecanismos que atuam na divergência entre o modelo institucionalizado e a dificuldade de participação nessas organizações.

Neste artigo apresentamos um estudo ${ }^{3}$ cujo objetivo foi o de investigar as forças psicossociais que atuam nas formas de participação dos trabalhadores rurais assentados em cooperativas. Estudamos uma cooperativa do Assentamento Mário Lago, localizado em Ribeirão Preto (SP). O caso foi considerado emblemático, pois a organização sofria com a baixa participação de seus associados: pelo menos a metade do quadro social estava inativo, em que os cooperados participavam pouco ou nunca haviam participado economicamente da organização; apenas $10 \%$ deles compareciam às reuniões para participar do processo de tomada de decisões. $\mathrm{O}$ contexto econômico e político da região tornava a relação dos trabalhadores com a cooperativa ainda mais complexa, pois a hegemonia do agronegócio coexiste com a pobreza nas periferias da cidade e nos assentamentos. Os assentados lutaram pela terra em busca de segurança e melhores condições de vida, mas ainda sofriam com a falta de condições mínimas para sobreviver no assentamento, tendo que recorrer a diferentes estratégias de trabalho fora dele.

Dividimos o artigo em quatro partes: primeiramente levantamos os estudos que tratam da participação em cooperativas de assentamentos rurais e propomos utilizar referencial da psicossociologia para analisar o problema; na segunda parte, destacamos o método eleito para a realização da pesquisa; na terceira parte, apresentamos os resultados e a discussão da pesquisa empírica realizada; e encerramos o artigo com as considerações finais.

\section{Sobre a participação em cooperativas: um olhar psicossociológico}

Antes de tratarmos dos principais resultados dos estudos que discutem a participação em cooperativas de trabalhadores rurais assentados, é importante entender as diferenças conceituais entre a participação em formatos organizativos autogeridos e heterogeridos. Guareschi (2008), Singer (2000) e Veronese (2009) destacaram os diferentes sentidos possíveis para o conceito de participação, que tem acompanhado as mudanças do trabalho ao longo dos séculos. Falar de participação nesses diferentes modelos organizativos implica, para os autores, considerar que

3 Agradecemos à Fapesp (Processo n. 2013/13229-6) pelo apoio financeiro à pesquisa. 
o seu mais alto grau de realização seria possível na autogestão, pois esta carregaria potencial emancipatório por demandar que os trabalhadores aprendam a participar coletivamente. Por meio dessa vivência os sujeitos criariam novas subjetividades que potencializariam a emergência de uma cultura de participação.

Lima (2010) considera que o discurso da participação na autogestão tem sofrido um refluxo ao alinhar-se cada vez mais a um tipo de participação semelhante ao modelo empresarial e heterogerido. Para o autor, estes formatos incorporam, ao menos parcialmente, o trabalho empreendedor como a nova roupagem das cooperativas. $\mathrm{O}$ discurso da participação, utilizado como estratégia de engajamento dos trabalhadores, passou a ter uma visão cooptada e assumiu significado de adaptação do trabalhador à necessidade de responder com eficiência às exigências do mercado, cuja flexibilidade justifica propostas de trabalho precárias, sendo de responsabilidade do sujeito saber adaptar-se a elas.

Essa crise de sentido da participação aparece desde os projetos políticos do Brasil, segundo Dagnino (2004). O contexto brasileiro passa por uma crise discursiva em relação à participação, fruto do que a autora chama de "confluência perversa" entre projeto neoliberal e projeto democratizante. O sentido de participação no projeto neoliberal é privatista e individualista, destituído do significado político e coletivo e apoia a solidariedade como comportamento moral para tratar questões como desigualdade social e pobreza. Por outro lado, veicula-se também no projeto democratizante um sentido de participação restrito à gestão pública, próximo do modelo empreendedorista de administração, que também se contrapõe ao sentido político da participação. Os deslocamentos desses sentidos de participação em ambos os projetos produzem efeitos que não são imediatamente evidentes. Mesmo de natureza antagônicas, são veiculados por mecanismos institucionais semelhantes, que obscurecem as diferenças e reduzem as contradições inerentes aos discursos.

Do ponto de vista dos trabalhadores, estudos como o de Azambuja (2007), Dal Magro e Coutinho (2008), Oliveira (2007) e Rosenfield (2003) mostraram que as vivências nesses empreendimentos têm diferentes sentidos possíveis, que nem sempre correspondem ao tipo de participação genuína em todos os processos decisórios da organização, tal como é preconizado pelo modelo da autogestão. Os resultados desses estudos dão indícios para entender que a discussão sobre os limites que separam uma cooperativa do tipo "autêntica", fiel aos princípios autogestionários, de uma cooperativa que reproduz o trabalho heterogerido e o discurso empresarial são imprecisos. Não só pelos diferentes discursos e sentidos da participação, como também pelas condições concretas que os trabalhadores têm para participar dessas organizações. Muitos desses problemas também foram identificados nas cooperativas em assentamentos rurais, especialmente em relação às dificuldades dos trabalhadores na gestão, na participação e na construção de um sentido do trabalho em maior conformidade com os princípios e valores da autogestão.

Há um conjunto de entraves de ordem objetiva e subjetiva, já constatados pela literatura (Barone, \& Ferrante, 2010; Costa, \& Bergamasco, 2003; D'Incao, \& Roy, 1995; Leite, Heredia, Medeiros, Palmeira, \& Cintrão, 2004; Sabourin, Oliveira, \& Xavier, 2007; Scopinho, 2012; Zimmermann, 1994) que podem explicar o problema da participação dos assentados rurais em cooperativas. Destacamos, entre os aspectos objetivos, a falta de infraestrutura dos assentamentos, os gargalos da comercialização e o baixo retorno financeiro desses empreendimentos. Quanto aos fatores de ordem subjetiva, os estudos apontam que as trajetórias de migração, a sucessão de vínculos enfraquecidos entre os sujeitos que carregam a marca da exclusão, as disputas internas, os sentimentos de incerteza e desconfiança também podem comprometer a permanência e a participação nas cooperativas. As experiências de convívio social trazem outra perspectiva de organização da cooperação e estabelecem um choque com a cultura de trabalho dos sujeitos, que viveram grande parte da vida em atividades assalariadas. Para acessar recursos como linhas de 
crédito, por exemplo, as cooperativas devem enquadrar-se em uma série de requisitos e a ausência de condições estruturais para atendê-los representa desânimo e frustração para os trabalhadores.

De acordo com Scopinho (2012), a falta de participação real dos trabalhadores repercute, objetivamente, na dificuldade de profissionalização da gestão e de inserção no mercado, geralmente mantendo essas organizações dependentes das políticas disponibilizadas pelo Estado. Do ponto de vista subjetivo, compromete os laços de confiança já muito fragilizados em função das constantes frustrações pelas quais os assentados passam antes e após a conquista da terra. Em razão disso, os sujeitos permanecem estabelecendo relações de cooperação informal, definidas por critérios de afinidade, e rejeitam o cooperativismo institucionalizado porque ele não ter correspondência com a realidade dos assentamentos.

É esse conjunto de constrangimentos culturais, econômicos e institucionais que os sujeitos buscam manobrar (Gaulejac, 2001). Para isso, o grupo tem função fundamental, pois pode oferecer o suporte afetivo que contribui para que o sujeito enfrente um universo carregado de contradições, segundo Enriquez (2001). O grupo participa de um constante jogo sutil de adaptações, alianças e estratégias de cooperação que são necessários para dar sentido à existência na organização e de seu sistema de regras e valores no cotidiano (Petit, \& Dubois, 2000). No entanto, quando esses mecanismos tendem a faltar, os vínculos sociais tornam-se fragmentados e a participação do sujeito no grupo é ameaçada. Barus-Michel (2004) explica esse fenômeno, já que cada vez mais os sujeitos aderem a um grupo pela força da necessidade econômica e pela imposição das leis do mercado. Essas relações fundamentam-se na desconfiança, em que o outro, a priori, é considerado concorrente, parasita ou perseguidor. Para a autora, esses sentimentos comprometem as negociações cotidianas e as construções dos laços sociais e da coesão grupal. Logo, se não há base segura de convivência e de projeção para o futuro, as relações de competição e desconfiança dificilmente são rompidas para a construção de uma participação real.

Por isso, Guareschi (2001) define ser importante conhecer como os sujeitos se relacionam e estabelecem laços entre si e com a organização, se a constituição do grupo é precedida ou não de uma "amarração conjunta". Barus-Michel (2004) considera a análise das relações de poder fundamental para compreender como o grupo se relaciona, pois os vínculos possuem caráter dinâmico e podem ser construídos de diferentes maneiras, ora fragilizados ora muito coesos, podendo modificar-se conforme os seus membros adquirem maior ou menor poder. Os indicadores de poder podem estar na expressão ou no silenciamento dos conflitos que podem provocar crises e a falta de participação. A autora dá como exemplo a invocação do discurso de coletividade que pode ser um mecanismo de ocultação das diferenças e de manutenção do poder. Por esse motivo, a confrontação entre as normas, os arranjos do cotidiano e os afetos do grupo são importantes para estudar o problema da participação. De acordo com a autora, quanto mais os três níveis estiverem em conformidade, mais os sujeitos poderão se expressar nas práticas do cotidiano e encontrarão mecanismos benéficos que garantam a sustentação afetiva e coletiva do grupo.

A partir dessa perspectiva foi possível, neste estudo, dirigir o olhar para uma organização que, teoricamente, está pautada em valores da autogestão e do cooperativismo que, não necessariamente, encontram conformidade com o sentido dado aos sujeitos ao trabalho e à organização. Mesmo sendo valores oriundos de lógicas organizativas distintas, contraditórias e conflitivas, eles se inscrevem na estrutura formal e revelam as formas de funcionamento real da organização.

\section{Método}

A pesquisa empírica, conduzida pela perspectiva qualitativa de Minayo (2001), foi construída por três momentos distintos e complementares: o de levantamento teórico/ 
bibliográfico/documental, o de realização de observações das reuniões da cooperativa e o de realização de entrevistas semiestruturadas com dez cooperados e dois mediadores institucionais do assentamento: um representante do Movimento dos Trabalhadores Rurais Sem Terra (MST), responsável pela ocupação da área e que coordenou o processo organizativo do Assentamento Mário Lago, e um agente de assistência técnica e extensão rural (ATER) - o profissional de referência que acompanhou cotidianamente, durante muitos anos, as rotinas da cooperativa e dos assentados, prestando orientações a respeito da produção e comercialização. Das observações registradas nos diários de campo foi estabelecido como critério de seleção dos entrevistados a participação, em maior ou menor grau, tanto das reuniões quanto da comercialização da produção com a cooperativa. As entrevistas foram encerradas quando o critério de saturação foi atingido e as informações deixaram de ser complementares. Todos os entrevistados foram indicados pelo presidente, que foi o informante-chave por conhecer mais profundamente o funcionamento da cooperativa. As entrevistas semiestruturadas seguiram um roteiro prévio, no qual foram abordadas questões sobre a trajetória de vida dos assentados antes e depois do assentamento, o histórico de participação na cooperativa, as motivações para ser cooperado, as relações com o grupo de associados, a percepção de vantagens e desvantagens de ser cooperado, o tipo de produção desenvolvida no lote e a relação com a cooperativa, a participação nas reuniões, as semelhanças e diferenças entre o trabalho assalariado e o trabalho cooperado, as projeções para o futuro da cooperativa e a relação com os movimentos sociais. A análise se deu pela triangulação das diferentes estratégias de levantamento de informações. Encontradas relações entre as fontes, esses conteúdos foram sistematizados por meio de uma listagem de categorias ou eixos temáticos que permitiu identificar padrões de relacionamento e de repetições entre os dados. Foram elencadas três categorias de combinações grupais, definidas pelas formas de participação dos cooperados: (1) coesão - participação - comercialização; (2) coesão - comercialização; e (3) dispersão; e quatro categorias que sintetizaram os sentidos que os trabalhadores davam à Cooperativa: (a) econômico; (b) laboral; (c) afetivo; e (d) político. As relações que se estabelecem entre essas diferentes categorias de sentidos e formas de participação permitiu refletir sobre o problema da participação dos trabalhadores rurais assentados na cooperativa analisada.

\section{Resultados e discussão}

O Assentamento Mário Lago faz parte do antigo território da Fazenda da Barra, reconhecido legalmente para fins de reforma agrária em 2007 após um longo processo de luta motivada pela sucessiva degradação ambiental da área. Formalizado na modalidade Projeto de Desenvolvimento Sustentável (PDS), o que implica a adoção da agroecologia e da cooperação como matrizes produtivas e organizativas que articulam produção de alimentos e conservação dos recursos naturais. Os lotes não são de propriedade individual dos assentados, pois o PDS prevê a concessão de uso coletivo da terra. Isso significa que a gestão do assentamento passa pela regulação do Incra e de outros agentes institucionais. O PDS da Barra abrigava 467 famílias organizadas em quatro núcleos, cada qual representado por movimentos sociais e projetos organizativos próprios, sendo um desses núcleos o Assentamento Mário Lago. Outra característica peculiar desse território é sua proximidade com o perímetro urbano de Ribeirão Preto, a $10 \mathrm{~km}$ do centro da cidade, o que facilita o deslocamento diário de muitas famílias, em busca de trabalho, educação, lazer, assistência social, entre outros recursos inexistentes no assentamento.

As bases produtivas do agronegócio tensionam a existência de um assentamento rural no contexto da região de Ribeirão Preto, segundo Ferrante, Barone e Duval (2012). Para os autores, a intensa disputa de interesses e de capital influencia não só as negociações das políticas de 
desenvolvimento rural na região, como também tem impactos substanciais nas experiências dos assentados com o cooperativismo.

A primeira experiência dos trabalhadores do Assentamento Mário Lago com o cooperativismo ocorreu por meio da comercialização da produção com o Programa de Aquisição de Alimentos (PAA), programa que cria mercados institucionais de compra pública de alimentos da agricultura familiar que são destinados à rede socioassistencial. A cooperativa estudada foi fundada em 2009 por um grupo de 23 assentados, com a finalidade de participar do PAA, cujo acesso também está condicionado à organização dos trabalhadores em cooperativas. Um dos traços diferenciadores desse grupo era o compartilhamento da religião evangélica, o que criava um modo de relacionamento peculiar com o MST, pois muitos valores religiosos eram refratários às condutas do movimento, como o engajamento político com partidos e movimentos sociais de esquerda.

$\mathrm{Na}$ época do estudo, a cooperativa não possuía sede própria, que funcionava provisoriamente na casa do presidente. Havia um barracão de construção inacabada e uma unidade de processamento de alimentos, que não funcionava por falta de licença da vigilância sanitária municipal que questionava a qualidade da água oriunda de poço artesiano. Apesar de estar sob uma área de recarga do Aquífero Guarani, os lotes mais distantes dos cursos d'água careciam de abastecimento para a produção nos períodos de estiagem. A cooperativa também dispunha de um caminhão para o recolhimento dos produtos que eram comercializados com os mercados institucionais. $\mathrm{O}$ quadro social era composto por 147 cooperados, 51\% de titulares mulheres e $49 \%$ homens, que trabalharam nas mais diversas ocupações antes de serem assentados ou que ainda permaneciam assalariados.

As pressões exercidas pelas dimensões institucional e material resultam em dinâmicas que precisam ser decifradas, segundo Barus-Michel (2004). O contexto econômico, social, as crises e as políticas de mercado articulam-se ao modo de participação dos sujeitos e às tomadas de decisões. Para a autora, o desânimo e a apatia dos sujeitos podem revelar um esgotamento que é produzido, principalmente, no plano dos constrangimentos estruturais da organização. Por isso a necessidade de desvelar as prescrições formais que regulam o cotidiano de uma organização.

Vimos que a composição institucional da cooperativa era formada por um conjunto de prescrições do Estado, fosse pela modalidade do assentamento ou pela inserção nos mercados institucionais, como o PAA. Essas políticas fazem parte de um determinado modelo de desenvolvimento rural que adota premissas como qualidade de vida, inclusão social, produção agroecológica e participação política, que deverão ser objetivadas por meio de formatos organizativos autogestionários como cooperativas e associações. Logo, o estatuto da cooperativa estava em conformidade com tais exigências, não sendo, portanto, um formato escolhido espontaneamente. Esses elementos já davam indícios de que os estruturantes institucionais da organização nem sempre encontravam correspondência com as condições objetivas que os sujeitos tinham para realizá-los, como no caso das relações de participação.

A carga burocrática e administrativa exigida pelo formato cooperativista tornou-se um problema para a cooperativa na medida em que todo o trabalho da gestão concentrou-se nas exigências de prestação de contas à Companhia Nacional de Abastecimento (Conab), órgão que regulava a participação das cooperativas no PAA, o que deixou a organização dependente do programa e comprometeu a busca por outras estratégias de inserção no mercado. Por isso, a dependência econômica do PAA, a burocracia do programa e seus constantes atrasos no repasse dos pagamentos foram descritos pelos entrevistados como os principais motivadores para que o trabalho no assentamento ficasse em segundo plano e fosse substituído pelo assalariamento na cidade.

Também o contexto político da região de Ribeirão Preto atuava como estrangulamento estrutural da cooperativa. Um entrevistado denunciava a discriminação que as pequenas 
cooperativas sofriam pelo poder público: “...chega uma cooperativa aí do agronegócio se apresenta em algum lugar, ela é aplaudida, o próprio governo abre as portas para ela, para tudo. Agora, e se vamos nós?" (Entrevistado 4). A falta de compromisso do poder municipal com os assentados também foi descrito pelos entrevistados como desmotivador para a participação na cooperativa.

Essas diferentes relações com as instituições de referência da cooperativa implicavam em algumas condutas e no modo como os sujeitos negociavam a participação no cotidiano da organização. Por isso, quando verificamos o que estava formalizado e o que realmente funcionava em relação à participação dos sujeitos na organização, observamos que as divisões dos cargos no Conselho de Administração cumpriam mera formalidade; na prática, as funções eram acumuladas pelo presidente. Mesmo o agente da ATER, que trabalhava há alguns anos com a cooperativa, afirmava desconhecer os membros que ocupavam formalmente esses cargos.

As reuniões serviam como um dos canais oficiais de comunicação do grupo, mas, segundo Petit e Dubois (2000), quando os seus desdobramentos permanecem nas redes informais de relacionamento, a comunicação fica comprometida. Poucos cooperados participavam das reuniões, que funcionavam apenas como um momento de transmissão de informações e decisões já tomadas pelo presidente. Tais ausências reforçavam a carga de trabalho centralizada no dirigente que, por sua vez, percorria todas as casas para recolher assinaturas e dar informações, quando as reuniões é que deveriam ser o verdadeiro espaço para que isso ocorresse. Essa era uma das evidências de que a participação era apenas simbólica, e não real. Os entrevistados relatavam sentir-se despreparados para lidar com as exigências organizativas da cooperativa, o que era realimentado pela ausência de participação e pelo desconhecimento sobre o cotidiano da organização. Se, por um lado, essa relação conferia comodidade aos cooperados, por outro, havia a desvantagem de concentrar todas as informações no presidente, que tanto podia tomar as decisões que achasse mais adequadas quanto também sofria com a sobrecarga de tarefas. Criava-se um círculo vicioso, pois os cooperados entendiam que as responsabilidades pela organização eram apenas do presidente, que também não descentralizava o trabalho da gestão alegando o desinteresse dos associados.

Em razão da comodidade, os entrevistados relatavam sentir autonomia em relação ao trabalho, pois assim poderiam dedicar-se apenas às atividades realizadas no lote ou na cidade. No entanto, tal comodidade criava entraves determinantes para a sobrevivência da cooperativa, pois pressupunha uma espécie de hierarquia invertida na qual um deveria trabalhar pelo coletivo, o que não só enfraquecia o grupo como também alimentava a dependência econômica dos mercados institucionais, uma vez que o presidente era considerado pelos cooperados o único capaz de conduzir as questões burocráticas exigidas pelo PAA, restando-lhe pouco tempo para explorar outros canais de comercialização.

O comprometimento da vida econômica da organização também fomentou uma divisão interna do grupo pelo critério de produtividade, entre os que produziam e comercializavam e os que não produziam e não comercializavam por meio do PAA. Apesar disso, para a cooperativa era interessante manter um quadro grande de cooperados, mesmo que formalmente, para facilitar o acesso a linhas de crédito. Portanto, essa suposta autonomia que apareceu no discurso dos entrevistados era bastante emblemática da falta de correspondência entre prescrição e realidade, entre cooperação institucionalizada e cooperação informal, regulada por comodidades que em um primeiro momento foram vantajosas para os cooperados, mas criou relações de dependência que passaram a ser um entrave para o desenvolvimento da cooperativa e uma das principais razões do afastamento dos trabalhadores.

A dimensão institucional e formal também era perpassada por uma dimensão relacional que contava a história da cooperativa e de sua identidade no sistema social, como as filiações religiosas, socioculturais e ideológicas. Os pertencimentos, para Petit e Dubois (2000), determinam clivagens e grupos de afinidades, e incluem os comportamentos imprevisíveis ou as adaptações que se referem 
às estratégias dos trabalhadores para responder às pressões da organização. Nesse caso, pertencer à cooperativa significava a possibilidade de desvencilhar-se da imagem de "sem terra", conforme descreveu uma das entrevistadas: "A gente se sente mais respeitado, onde a gente chega e fala "é da cooperativa' já tem outra [aceitação]" (Entrevistada 2). Os sujeitos tentavam ressignificar por meio da organização a imagem de assentado vinculada no imaginário social à miséria, exclusão e violência, que ainda era atrelada ao assentamento: "Na cidade as pessoas julgam muito os produtos da gente 'ah, eu não vou comprar porque se eu comprar eu vou ajudar um sem terra.' A gente sabe que tem esse preconceito até o dia de hoje" (Entrevistada 3).

Para Gaulejac (2006), uma conjunção de fatores, objetivos e subjetivos, produz a estigmatização da pobreza, especialmente em um contexto social individualista no qual a competição e a excelência são exaltadas em prejuízo daqueles que não se ajustam a esse padrão. Para o grupo estudado, havia uma complexa burocracia exigida na forma de documentos que cumpriam função de controlar os investimentos públicos, como também de legitimar a seleção daqueles que realmente mereciam acessar os programas. Conforme destaca o autor, todo o processo burocrático que se desenrola para o acesso às políticas públicas pode ser considerado uma relação de violência, uma sucessão de desprezos por aqueles considerados "gente de bem" e pelas instituições, e que se acumulam em função da pobreza estar atrelada no imaginário social à desqualificação e, especialmente no caso estudado, à criminalização da luta pela terra. Por isso, além da instituição impor a necessidade do sujeito provar que é merecedor do benefício, mesmo que seja seu direito, ele deverá mostrar-se disposto a inserir-se entre os "bons trabalhadores", que respeita a legalidade ainda que toda uma ordem de constrangimentos inviabilizem as mínimas condições de vida.

Era necessário considerar que a conquista da terra também conferiu um sentido material e simbólico de segurança aos sujeitos. Uma das entrevistadas trabalhava na cidade e poderia viver na casa da sua mãe que ficava ao lado do seu local de trabalho. Ela retornava todos os dias para o assentamento: "...eu acho que na cidade você acaba indo no movimento deles, parece que você tem a obrigação de estar em um patamar. Aqui não, a vida é muito mais simples" (Entrevistada 7). Como lembra Gaulejac (2006, p. 108) “...frente a essas feridas, o sujeito busca salvaguardar sua unidade, conservar, apesar de tudo, uma imagem aceitável de si mesmo. Este é o sentido de seu combate pela dignidade". Mesmo não trabalhando no campo, o fato de residir no assentamento conferia pertencimento a esse espaço, que comportava significados que iam além da função produtiva da terra.

Apesar de cumprir função de pertencimento e reconhecimento, a dimensão coletiva da cooperativa aparecia como retórica nos discursos dos entrevistados, embora se referissem a "cooperativa do povo" em alguns momentos, ela era vivida pelo grupo como a "cooperativa do presidente". Essa dinâmica foi importante na compreensão da indiferenciação entre presidente e organização, em que vida pessoal e trabalho misturavam-se não apenas no espaço físico de sua casa-sede da cooperativa, mas especialmente na dimensão subjetiva. Um dos elementos da coesão grupal mantinha-se pelo papel desempenhado por essa figura, que conduzia a cooperativa por meio de comportamentos valorizados pelo grupo:

É por causa da honestidade, só por isso. A cooperativa é uma coisa que é como uma família dentro de casa. Se você não tem confiança na pessoa, não tem como você colocar a pessoa dentro de casa, porque amanhã ou depois está colocando um bandido (Entrevistada 3).

A organização espacial da cooperativa foi outro elemento de análise, uma vez que a arquitetura pode revelar o que Barus-Michel (2004, p. 138) descreve como "espírito da casa". Segundo a autora, os diferentes pertencimentos dentro da organização podem confundir o que é do sujeito e o que é do outro. O presidente personalizava os valores enaltecidos pelo grupo, criando 
um imaginário coletivo em que cooperativa e presidente eram concebidos como uma coisa só. Para Lévy (2001) a fusão da identidade do líder com a organização tem como efeito a atualização da coesão e da adesão maciça às restrições e prescrições. A intensa confiança no presidente, que cumpria um papel de liderança carismática no grupo, pois concentrava além de conhecimento para gerir a cooperativa, características morais muito valorizadas pela religião evangélica. A falta de participação também revelou-se como desconfiança em relação aos sistemas sociais, dado as sucessivas frustrações e projetos mal sucedidos que os sujeitos já tiveram ao longo do tempo. $\mathrm{O}$ grupo fechava-se no presidente e acomodava-se a ele, que tinha sido um dos poucos a não romper com o sistema de valores e de condutas apreciadas pelo grupo.

E qualquer questionamento de mudança dessa condição era sentida como ameaça à continuidade da cooperativa, como afirmou uma das entrevistadas: “...se o [presidente] sair da presidência da cooperativa, eu saio também. Eu sai de outra cooperativa para vir para cá só por causa do [presidente]" (Entrevistada 3). A sacralização de uma determinada situação no grupo pode resultar em uma "pane" no funcionamento da organização, pois a ausência de questionamentos engessa a possibilidade de contestação, de reajuste do grupo em função das circunstâncias. "A mínima palavra... é sentida como um golpe intolerável, e como uma ameaça para o conjunto das ideias e das crenças que servem de fundamento ao edifício" (Lévy, 2011, p. 134). Uma aparente solidez conferida pelo estatuto familiar à organização pode ocultar falhas e contradições que fragilizam o grupo, como as relações de dependência do núcleo familiar e certo imobilismo dos demais membros.

Por isso, afetivamente a cooperativa cumpria função de pertencimento, mas que não tinha ligação com o trabalho dos sujeitos, e sim com a possibilidade de ressignificar a imagem socialmente desvalorizada de pobreza e de sem-terra, uma possível forma de identificação com a saída da condição de exclusão e de violência. Outro elemento que compunha tal pertencimento eram os valores identificados na organização e que eram exaltados pelo grupo. Nesse caso, os valores eram personificados pelo presidente.

Esses padrões de participação instrumental, os pertencimentos e os valores que compunham a dinâmica da cooperativa foram organizados em categorias. Levamos em consideração que a organização informal dos grupos pode compartilhar valores e sentidos semelhantes ou conflitantes, pois nem sempre os grupos de pertencimento estão ligados à organização. A organização formal da cooperativa pautava-se em valores e princípios do cooperativismo que eram distintos dos valores que organizavam o grupo informalmente.

Foi possível identificar nos elementos empíricos alguns padrões de participação do grupo, que optamos por chamar de combinações grupais. Combinações porque não se tratam de subgrupos propriamente ditos, mas sim combinações que se referiam às diferentes formas que os sujeitos participavam da organização e aos sentidos que atribuíam ao trabalho. A divisão interna da organização nessas combinações grupais indicava que a dinâmica da cooperativa não se restringia às disposições formais previstas em estatuto, pelo contrário, as negavam ou as ajustavam de acordo com as relações de confiança e comodidade.

Todos os cooperados participavam da cooperativa de modo instrumental. O que caracterizava os diferentes arranjos informais na organização eram as relações de produção/comercialização, a frequência nas reuniões e os vínculos de confiança no presidente. Assim, identificamos três tipos de combinações grupais: (1) coesão - participação - comercialização; (2) coesão-comercialização; e (3) dispersão.

A primeira combinação, coesão - participação - comercialização, referia-se ao grupo dos primeiros cooperados que organizaram a fundação da cooperativa e que estabeleciam relações de intensa confiança com o presidente, bem como possuíam afinidade e partilhavam de valores comuns da religião evangélica. A forma de participação era manifestada pela presença frequente 
dos cooperados nas reuniões e na regularidade de entrega dos produtos para os mercados institucionais.

Na segunda combinação, coesão - comercialização, os sujeitos também partilhavam os mesmos valores e intensa confiança em relação ao presidente. Contudo, a forma de participação aqui se restringia à entrega de produtos para a comercialização por meio da cooperativa. Os entrevistados justificavam não ser necessário participar das reuniões, pois o presidente tomava as melhores decisões pelo grupo.

O terceiro grupo, dispersão, não possuía relação de coesão aparente com os outros dois grupos. Isso porque, embora fosse um grupo que compartilhava dos mesmos valores, essa relação era difusa, pois alguns desses sujeitos já haviam saído do quadro de cooperados e retornaram, ou comercializavam a produção para outras cooperativas dentro ou fora do assentamento. A produção no lote estava em segundo plano e era entregue à cooperativa esporadicamente. Em outros casos, não havia o que comercializar posto que a produção da família estava restrita ao autoconsumo. Essa combinação aproximava-se de um tipo indiferente, em que o pertencimento à organização cumpria função secundária e pouco importante, uma função "muda", segundo Rouchy e Desroche (2005). A cooperativa não cumpria função econômica ou fazia parte dos projetos de futuro dos cooperados. A falta de água para produzir, o assalariamento e outras razões de ordem pessoal eram determinantes para que esses projetos de trabalho estivessem fora da cooperativa. Eram estratégias adaptativas encontradas pelos sujeitos para lidar com as insuficiências do assentamento e da organização. Para o grupo, se havia alguma ligação com a organização, esta decorria exclusivamente do compartilhamento de valores da religião.

Para a primeira e a segunda combinações, o terceiro grupo era visto como divergente e que, por ser improdutivo, era um entrave para a resolução de problemas que dependiam da anuência de todos os associados. Também a possibilidade de perda do presidente causava temor pela possível fragmentação e descontinuidade da cooperativa, caso ele deixasse de assumir tal função. Esses dois grupos estavam ligados não só pela religião, mas também pelo conhecimento técnico do presidente que se convertia em ganhos para a comercialização da produção e pelo sentido de pertencimento e restauração da identidade. Possivelmente, mesmo se não houvesse a cooperativa, eles estabeleceriam relações de cooperação informal e ajuda mútua, independente da formalização da organização.

Foram identificadas outras quatro categorias que sintetizavam os sentidos que os trabalhadores davam à cooperativa: (a) econômico; (b) laboral; (c) afetivo; e (d) político. Um dos principais sentidos atribuídos pelos sujeitos à cooperativa era o econômico, pelas vantagens e desvantagens ligadas à comercialização do que eles produziam. Para todos os grupos, a Cooperativa era vista como um canal que facilitava o escoamento da produção pela inserção no PAA. Participar da cooperativa significava comercializar ou não a produção. Por isso, para todos os grupos, a dimensão da participação estava ancorada ao sentido econômico.

Outra categoria de sentido identificada relacionava-se ao modo como os sujeitos entendiam o trabalho na cooperativa, chamada de sentido laboral. Os cooperados entendiam o trabalho na cooperativa como objeto de responsabilidade do presidente em função do seu conhecimento e das características pessoais que inspiravam confiança, embora soubessem que a organização formal previa que outros membros assumissem cargos na gestão. Também porque ainda entendiam o trabalho referenciado no assalariamento e na heterogestão, embora muitos rejeitassem esse modelo. Portanto, os sentidos atribuídos ao trabalho estavam fora da cooperativa pela separação entre gestão do trabalho e gestão da organização. A gestão do trabalho estava relacionada às atividades individuais no lote ou às atividades assalariadas na cidade, e a gestão da cooperativa cabia apenas ao presidente. Mesmo a autonomia que os cooperados sentiam em relação à cooperativa não tinha relação com os processos de trabalho autogeridos, como a democracia e a participação, mas sim 
com a comodidade da gestão estar sob os cuidados do presidente. A verdadeira autonomia que os sujeitos sentiam no trabalho estava relacionada ao trabalho individualizado no lote, pois era nesse espaço que eles podiam controlar seu próprio tempo sem a interferência direta de uma chefia, noção de autonomia esta que é típica das relações de trabalho do camponês.

O sentido afetivo referia-se aos significados que eram atribuídos à cooperativa como fonte de identificação e pertencimento, pela tentativa dos sujeitos de se desvincularem da imagem socialmente desvalorizada do assentamento e também pelos valores religiosos, divergentes dos valores do movimento social. Os sujeitos buscavam construir na cooperativa um sentido de pertencimento e de identidade que sustentasse os valores religiosos e as condutas apreciadas, como a honestidade e a idoneidade, além de uma identidade que os diferenciasse da imagem estigmatizada da pobreza e da criminalidade, que também era reforçada pela maneira com a qual os órgãos institucionais os tratavam com negligência e desconfiança.

Finalmente, uma quarta categoria de sentido foi identificada: o politico, que se referia aos sentidos atribuídos ao papel político da cooperativa e que era divergente do sentido preconizado pelos princípios autogestionários. Para os entrevistados, a função política não aparecia como papel da cooperativa, nem mesmo para aqueles que tiveram história de militância. O sentido político, nesse caso, era negativo e os sujeitos o relacionavam ao papel do MST. Apesar desse estranhamento com o movimento, o fato de haver um "fechamento informacional" sobre o conflito, nos termos de Machado (2002), a relativização da crítica ao MST indicava que os sujeitos reconheciam o papel do movimento na luta pela terra, cuja mobilização foi fundamental para construção do assentamento. Os que participavam de modo disperso também entendiam a cooperativa como um instrumento econômico, cujo sentido do trabalho era externo a ela, sem relação com a função política e sem sentido afetivo.

O projeto político era indiferente para os trabalhadores que optaram por se associar à cooperativa, por ser a única opção econômica possível. De algum modo ela representava segurança em um ambiente marcado por incertezas e, conforme afirmou Rosenfield (2003, p. 22) a relação com o coletivo "...dá-se sob forma de subordinação, uma vez que a cooperativa autogerida lhes aparece como 'tábua de salvação' e não como um projeto”. Contudo, essa segurança diluía-se à medida que o PAA atrasava a liberação dos pagamentos e a sobrevivência dos cooperados era comprometida. A burocracia do programa repercutia no enfraquecimento da única fonte de referência e sobrevivência.

Para os dois primeiros grupos os mesmos sentidos eram compartilhados, pois os sujeitos estabeleciam algum tipo de relação com a cooperativa, mesmo que instrumental, e a organização retornava como base identitária e de pertencimento aos sujeitos. Porém, para o grupo da dispersão, por não haver qualquer relação de participação, os sentidos eram produzidos de modo difuso porque estavam desvinculados da organização.

Os cooperados compartilhavam de um mesmo campo de valores que não eram do cooperativismo e da autogestão. O sentido atribuído à cooperativa era articulado por esses diferentes elementos, pelas vivências e negociações dos sujeitos dentro do grupo em relação às regras e prescrições institucionais e também pelos valores e identificações por meio dos quais construíam diferentes modos de participar da organização. A instrumentalidade da participação pode ser explicada pela falta de correspondência entre o modelo organizativo que foi imputado aos sujeitos, os sentidos atribuídos ao trabalho e à cooperativa, e os valores que davam coesão ao grupo.

Apesar de cada combinação referir-se aos diferentes modos com os quais os sujeitos participavam, todas elas estavam atravessadas pelo mesmo campo de valores da religião evangélica, valores que tanto alimentavam a dimensão relacional da cooperativa quanto estavam 
personificados no líder carismático. Suas condutas, valores e conhecimentos davam a sustentação da gestão do empreendimento e produziam um imaginário social sobre a cooperativa.

Maciel (2009) reconhece que as relações afetivas que são estabelecidas entre familiares, grupos de afinidade e entre pessoas da mesma religião produzem uma lógica de economia moral, de ajuda mútua e cooperação informal. Portanto, não há um projeto organizativo que corresponda ao estatuto da organização, ao menos em termos dos valores. Essa talvez seja a maior lacuna que deixa em evidência o caráter compulsório do modelo formal adotado pela cooperativa e das estratégias construídas pelos assentados diante dos constrangimentos.

Não havia correspondência entre as regras prescritas no estatuto da organização e as práticas cotidianas dos cooperados, pois estes criaram uma dinâmica adaptativa e de alianças dentro do grupo. Ancorada na confiança e na comodidade, essa dinâmica tinha como eixo central os valores religiosos personificados na liderança carismática do presidente. Portanto, a falta de legitimidade da regra de participação podia se dar tanto pela compulsoriedade do formato organizativo quanto pela dinâmica de relacionamento do grupo e dos valores que eram compartilhados.

\section{Considerações finais}

Os problemas identificados no processo organizativo da cooperativa não só corroboraram os achados da literatura como também reforçaram a constatação de que o modo como as políticas de desenvolvimento rural têm sido pensadas e praticadas no país reproduzem um cooperativismo típico e ocasional diante das necessidades dos trabalhadores de acessarem as políticas públicas em busca de recursos financeiros. A organização da rotina dos sujeitos para cumprimento das condicionalidades mostrou que não havia alteração estrutural de suas condições de trabalho e de vida. Também os sentidos atribuídos à organização não tinham ligação com o sentido de trabalho institucionalizado pelas políticas públicas e inspirado nos valores da autogestão.

Por outro lado, a cooperativa cumpria papel simbólico de dignificar esses trabalhadores, cujas trajetórias de vida sempre foram marcadas pela exclusão. As redes de confiança suavizavam os impactos da pobreza e das relações de dependência com os mercados institucionais, mas os assentados ainda sentiam-se fragilizados por não conseguirem manter uma produção de subsistência que poderia materializar a condição de produtor rural e reforçar os laços de reciprocidade. Portanto, as desproporções entre as forças psicossociais se davam nos três níveis: no institucional, pelo projeto de cooperativismo e de desenvolvimento rural; no organizacional, pelas condições concretas de efetivação desse projeto; e no relacional, pelas diferentes estratégias que os sujeitos encontram para enfrentar esses constrangimentos, tensionar as contradições dos outros níveis e negociar entre si o modo como essas prescrições seriam executadas, e que são sustentadas por outros valores que não os da autogestão.

Se os sentidos refletem os modos de viver e de existir dos grupos, bem como revelam as relações de poder estabelecidas entre os sujeitos, ficou claro o porquê de todo esse esquema de forças referentes ao processo organizativo da cooperativa estar relacionado a outros valores e modos de participação que não os preconizados pela autogestão. $\mathrm{O}$ seu funcionamento estava em conformidade com o modo como os sujeitos davam sentido ao trabalho e ao significado que a organização tinha na vida deles.

O assentamento rural é uma realidade complexa porque comporta significados que vão muito além do espaço produtivo da agricultura. Quando o cooperativismo é eleito como política principal dos assentamentos de reforma agrária, não se problematizam os conflitos agrários e as condições dos trabalhadores de acesso aos direitos, pois se entende que a inserção produtiva no mercado é que atuará para minimizar os impactos da exclusão social desses sujeitos. $\mathrm{O}$ acesso às 
políticas, nas condições em que ocorre, reforça o caráter individualizante e não garante o exercício real da cidadania pelos sujeitos; ele produz subjetividades autorreferenciadas, em que o sujeito é a referência tanto por sua situação de pobreza quanto para cumprir com requisitos para garantir os seus direitos. No caso estudado, essa relação era ainda mais contraditória pelo contexto econômico e político de Ribeirão Preto, pois o assalariamento na cidade era estratégia de reprodução da vida, como também seus atrativos eram maiores em relação ao que o assentamento oferecia. A coexistência dessas duas realidades evidenciava a ambiguidade entre a identidade de trabalhador rural assentado e a de assalariado urbano.

Do ponto de vista teórico, o estudo também evidenciou a dificuldade de ter um modelo teórico de referência para pensar as relações de trabalho nos assentamentos. Apesar de já existir um campo de estudos do cooperativismo dos assentamentos rurais, os modelos que respaldam as pesquisas também são insuficientes para considerar toda a complexidade desse universo ou propor saídas muito diferentes das estratégias já ensaiadas pelos próprios trabalhadores. Por isso esta investigação pode contribuir para reforçar a necessidade da psicologia social do trabalho em ampliar e consolidar a compreensão dos sujeitos que vivem e trabalham no mundo rural.

\section{Referências}

Azambuja, L. R. (2007). Os sentidos do trabalho autogerido: um estudo a partir dos trabalhadores de cooperativas de economia solidária. Dissertação de Mestrado, Programa de Pós-Graduação em Sociologia, Universidade Federal do Rio Grande do Sul, Porto Alegre.

Barone, L. A., \& Ferrante, V. L. S. B. (2010). Assentamentos rurais em São Paulo: estratégias e mediações para o desenvolvimento. Dados, 55 (3), 755-785.

Barus-Michel, J. (2004). O sujeito social. Belo Horizonte: PUC Minas.

Costa, C. M. O., \& Bergamasco, S. M. P. P. (2003). Processo de organização da produção em assentamentos rurais no Brasil: A Fazenda Pirituba/SP. In S. M. P. P. Bergamasco, M. Aubrée, \& V. L. S. B. Ferrante (Orgs.), Dinâmica familiar, produtiva e cultural nos assentamentos rurais de São Paulo (pp. 125-156). São Paulo: Incra.

Dagnino, E. (2004). Construção democrática, neoliberalismo e participação: os dilemas da confluência perversa. Política ES Sociedade, 3 (5), 139-164.

Dal Magro, M. L. P., \& Coutinho, M. C. (2008). Os sentidos do trabalho para sujeitos inseridos em "empreendimentos solidários". Psicologia em Estudo, 13 (4), 703-711.

D’Incao, M. C., \& Roy, G. (1995). Nós, cidadãos: aprendendo e ensinando a democracia. Rio de Janeiro: Paz e Terra.

Enriquez, E. (2001). O papel do sujeito humano na dinâmica social. In M. N. M. Machado, E. M. Castro, J. N. G. Araújo, \& S. Roedel (Orgs.), Psicossociologia: análise social e intervenção (pp. 27-42). Belo Horizonte: Autêntica.

Ferrante, V. L. S. B., Barone, L. A., \& Duval, H. C. (2012). O final de um ciclo? Reflexões sobre assentamentos rurais no Estado de São Paulo. Espaço de Diálogo e Desconexão, 5 (1), 1-28.

Gaulejac, V. (2001). Psicossociologia e sociologia clínica. In J. N. G. Araújo, \& T. C. O. Carreteiro (Orgs.), Cenários sociais e abordagem clínica (pp. 35-48). São Paulo: Escuta.

Gaulejac, V. (2006). As origens da vergonha. São Paulo: Via Lettera.

Guareschi, P. (2001). Relações comunitárias, relações de dominação. In R. H. F. Campos (Org.), Psicologia social comunitária: da autoridade à autonomia (pp. 81-99). Petrópolis: Vozes.

Guareschi, P. (2008). Prefácio. In A. F. Silveira, C. Gewehr, L. F. R. Bonin, \& Y. L. M. Bulgacov (Orgs.), Cidadania e participação social (pp. 1-4). Rio de Janeiro: Centro Edelstein de Pesquisas Sociais.

Leite, S., Heredia, B., Medeiros, L. Palmeira, M., \& Cintrão, R. (2004). Impactos dos assentamentos: um estudo sobre o meio rural brasileiro. São Paulo: Unesp, 2004.

Lévy, A. (2001). Ciências clínicas e organizações sociais. Belo Horizonte: Autêntica. 
Lima, J. C. (2010). Participação, empreendedorismo e autogestão: uma nova cultura do trabalho? Sociologias, 12 (25), 158-198.

Maciel, M. C. (2009). O individual e o coletivo nos assentamentos: entre o ideal e o real. Retratos de Assentamentos, 12 (1), 217-242.

Machado, M. N. M. (2002). Entrevista de pesquisa: a interação pesquisador/entrevistado. Belo Horizonte: C/Arte.

Minayo, M. C. S. (2001). Pesquisa social: teoria, método e criatividade. Petrópolis: Vozes.

Oliveira, F. (2007). Os sentidos do cooperativismo de trabalho: as cooperativas de mão-de-obra à luz da vivência dos trabalhadores. Psicologia E⿱ Sociedade, 19 (n. esp.), 75-83.

Petit, F., \& Dubois, M. (2000). Introdução à psicossociologia das organizações. Lisboa: Piaget.

Rosenfield, C. L. (2003). A autogestão e a nova questão social: repensando a relação indivíduo-sociedade. Civitas, 3 (2), 395-415.

Rouchy, J. C., \& Desroche, M. S. (2005). Instituição e mudança: processo psíquico na organização. São Paulo: Casa do Psicólogo.

Sabourin, E., Oliveira, M. N., \& Xavier, J. H. V. (2007). Lógica familiar e lógica coletiva nos assentamentos de reforma agrária do Brasil: o caso do município de Unaí (MG). Estudos Sociedade e Agricultura, 15 (1), 23-61.

Scopinho, R. A. (2012). Processo organizativo de assentamentos rurais: trabalho, condições de vida e subjetividades. São Paulo: Annablume.

Singer, P. I. (2000). Economia solidária: um modo de produção e distribuição. In P. I. Singer, \& A. R. Souza (Orgs.), A economia solidária no Brasil: a autogestão como resposta ao desemprego (pp. 11-28). São Paulo: Contexto.

Veronese, M. V. (2009). Subjetividade, trabalho e economia solidária. Revista Crítica de Ciências Sociais, 84, 153-167.

Zimmermann, N. C. (1994). Os desafios da organização interna de um assentamento rural. In L. Medeiros, M. V. Barbosa, M. P. Franco, N. Esterci, \& S. Leite (Orgs.), Assentamentos rurais: uma visão multidisciplinar. São Paulo: Unesp.

\section{Endereço para correspondência}

thainaragm@gmail.com, scopinho@ufscar.br
Recebido em: 20/05/2015

Revisado em: 22/04/2016

Aprovado em: 13/06/2016 